\title{
AN HISTORICAL REVIEW OF ARTIFICIAL FOREST PRUNING
}

\author{
By James D. Curtis, M.C.S.F.E. ${ }^{1}$
}

$\mathrm{T}$ HE ARTIFICIAL pruning of forest trees has probably been practised since time immemorial, although the method and purpose has differed very widely from time to time. Evelyn (1706) states that the Greeks early recognized its benefits and believed that a goddess presided over it.

ENGLAND 1600-1900

England was apparently the first country to initiate the use of pruning as a silvicultural measure. Due to the fact that oak and beech were the most important trees at that time, an effort was made by advocates of pruning to produce straight trees rather than clear wood, by virtue of these species being much in demand for ships. Ship building was flourishing in the seventeenth and eighteenth Centuries and the demand, especially for oak, was widespread; consequently all efforts were directed toward this tree.

Lawson (1623) and Evelyn (1706) were among the first to make recommendations on pruning, although their object in general was to avoid rottenness and to produce thrifty and handsome trees. There were other men, however, such as Nichol (1799) who considered the pruning of trees by saws, chisels, and hatchets too drastic and unnecessary to produce the desired result. As a consequence, a new line of thought developed which gained much support and favor.

The system of pruning advocated by these men was known as "finger budding" or "foreshortening." It consisted of pinching off the buds from branches which were considered too large and required a check in growth, or from branches which were to be eliminated altogether. This method was very favorably received among timber growers since, they maintained, no large wounds were made which had to heal, and the operator was still afforded a chance to regulate more or less the shape of his tree. Pruning close to the bole was condemned for reasons which were supposed to be sufficiently conclusive to uphold this view, but it is doubtful if they were ever substantiated by thorough investigation.

From about 1670 on, there was apparently nothing of importance written on pruning until the end of the eighteenth century. For a good many years the system of "finger" pruning appears to have been more of a logical method of approach for what was considered essential. That this

1 Department of Forestry, Massachussetts State College, Amherst, Massachusetts. 
was a natural outcome of an endeavour to produce straight oak is easily appreciated, and evidently timber growers and arborists were content with this method of culture.

1880-1900. During the 19th century, when estate owners were beginning to create plantations of conifers on a sizeable scale, pruning once more began to be prominent in discussions and literature of that period. Although many supporters of the "finger budding" school adhered to their original method, believing it to be the best means to an end, another group carried out investigations along more radical lines. The majority of pruners still supported the view of enhancing vigor and the shape of the tree, hardwood and conifer, but there were not a few who realized the benefits of wood quality. Some believed that, in order to obtain high quality wood, the tree should be continually finger-budded until the lower bole was freed of branches, a gradual process. Others, however, resorted to direct means of pruning as we now know it. For instance, in the former group Hutchison (1868) contended that a cup is formed when close pruning is practised, which induces rot, but by "pointing" or "finger pruning" a few branches at each operation with the aid of a long-bladed handknife, the same result is accomplished in a safer way.

Pontey (1805), Gillanders (1887), and Michie (1888) were among the first to advance the idea of pruning for quality alone, and were probably responsible, to a large extent at least, for its initiation in England. William Pontey took the initiative in recognizing the inability of most trees to rid themselves successfully of branches, and the consequent defects caused by large rotting limbs of timber species. In his "Forest Pruner" he set forth many original ideas and rules for forest owners, which he explains in detail as a logical approach to the question of knotless timber.

Michie published a comprehensive work on forestry, and in it devoted considerable space to pruning. Although there was a general tone of resorting to that which brings about a better shape to the tree's crown and enhancement of vigor, Michie pointed out the increased value produced by pruning, declaring that it would unquestionably result in better lumbering than unpruned stems. He stressed the fact, however, that no limbs should be removed from a tree unless the purpose could be definitely justified, that it was unwise to upset the balance of a tree unless absolutely necessary. Michie was perhaps among the first who advocated the use of pruning in plantations in England, but did so in such conservative tones that it is evident he did not subscribe to the treatment as a regular practice. His contribution to pruning literature of the time was valuable in that he carried out extensive investigations, so that most of his theories were cor- 
roborated by close observations over a number of years. Many of the earlier writers failed in this regard, and consequently their decisions on physiological subjects can not be given too much weight.

According to Michie, pruning was first practised to any extent in England about 1848, and on'e of the first regular systems employed was that propounded by Gavin Cree. Cree's method consisted of cutting off one-half the length of all the branches from the base to the tip of the tree, which he claimed would slow up the growth of the side branches and send more sap up the stem. This resulted in such narrow annual rings that it was never practised extensively. McCorquodale (1884) points out that pruning was abandoned in the English Crown Forests in 1854, but that the same method of pruning by "fore-shortening" branches was continued to a large extent on private lands and estates, to produce straight timber. This, he explained, assisted in "shaping up" the tree when it was only eight feet high, and continued until a good clear log was obtained.

Forest pruning, then was carried on by various methods until the end of the nineteenth century by individual estate owners over the greater part of England and Scotland. There was little attempt to standardize the practice, and most of the trees pruned were hardwoods. That this was inevitably brought about by the fact that there was little intensive forestry practiced on crown land before 1900, and that timber owners had to rely, for the most part, on knowledge gained by practical men in charge of their land, can be readily understood. High quality production was not a prime object, and plantation owners were chiefly concerned as pioneers in that work, with keeping their forests vigorous and normally productive. Furthermore, a large portion of the woodlands and forests were composed of the broad-leaved species, and the information gathered in reference to the pruning of limbs from these trees was very conflicting. The result was an indifferent attitude towards pruning as a silvicultural necessity for highquality wood on short rotations.

\section{CONTINENTAL COUNTRIES 1800-1900}

Contrary to general belief, the practice of pruning in Europe was initiated in Belgium and Holland and gradually spread from those countries to France and Germany. Poland, Italy, and Sweden followed in Germany's footsteps. The depletion of forests in the Middle Ages and the subsequent scarcity of wood produced a demand for mass production, and the idea of quality was ignored. The thought of fuel was uppermost in these countries, especially Germany. During the nineteenth century, however, when Germany was replacing many of her high forests with the selection type with a view to producing greater volume, May (1888) points out that from 1848 . 
to 1884 coal output had increased from 4.4 million to 57.0 million tons. This cheap mining and transportation of coal decreased with the fuel-wood market over all Europe; and Germany, in common with her neighbors, sought different methods of silviculture, which would bring about highgrade lumber from her forests. Belgium, Holland, France, and Germany embraced the practice of pruning as the solution to their common problem -quality production. In the first three of these countries topographic features, together with soil and climate, allowed the coppice-with-standards system to be practised to good advantage, and this method came to the fore as the outstanding and most commonly employed silvicultural measure of the time. By confining the crown to a small section of the stem through pruning, quality saw-timber was produced on the standards, while tops and understory produced fuel. It was at this time that the pruning corps were formed. Travelling from place to place when felling in the underwood was in progress, they would prune the oak standards and distribute the prunings as faggot fuel.

Germany was the only country in Europe to investigate and practise pruning on a thorough and extensive scale during the nineteenth century. Although adjacent countries had already been pruning for a number of years before Germany realized the advantages accruing from it, German foresters were able to take advantage of the knowledge already gathered by foreign investigators and made rapid progress in pruning technique. For instance, according to May (1888), Sierstorpff made a study in Belgium and Holland in 1796. He observed that large limbs were first girdled prior to pruning, and the use of the copper plate on large limb cuts to enhance the rate of healing. Klein, in 1826, discovered that Belgian foresters were employing a "boutoir" or chisel-like insrtument, and a sickle-shaped tree knife, as well as the hatchet. He learned further that the old method of leaving stubs, in vogue until 1826, had not been abandoned and that, even with large limbs, cuts were being made close to the bole.

May (1888) points out that Dr. Anton Beil also made an investigative tour into adjacent countries in order to secure information on pruning with a view to introducing new methods and technique into Germany. The Dutch had found that leaving stubs resulted in rot being enclosed within the tree, while Des Cars in France had instituted a division of crown classes for coppice forest standards which allowed easier approach to the carrying out of pruning in that type of forest. The Vicompte de Courval (1865) was largely responsible for the pruning technique of the period, introducing the modern bill-hook, improved chisels, and the new types of saws. In addition, he discovered the importance of the season of pruning and the use of coal tar as a preventative against rot. 
The information gathered by German foresters from those of Belgium, Holland, and France supplied the impetus necessary to carry Germany on an intensive investigative program of forest pruning about the middle of the 19th century. George Alers was perhaps among the foremost responsible for the progress made. The thoroughness and diligence with which Alers sought new methods and applications of pruning to different species, ages, and sites of trees contributed in no small way to the extensiveness of additional experimental work and interest in pruning. Alers' "Flugelsage" (1874) or pole saw, the first of its kind, substantially reduced pruning costs, and other countries soon adopted this method for high pruning, in some instances as high as 60 feet. This method of removing branches high on the stems proved faster than any heretofore employed, and did much to establish pruning on a sound financial and practicable basis.

In 1868 Alers published the result of many of his investigations, stressing the value of lumber from pruned trees, the slowness and tardiness of natural self-pruning, and the applicability of artificial pruning to Norway spruce and Scots pine. He formulated rules which met with widespread approval and were universally adopted.

Alers was the first man to balance the cost of pruning against the ultimate return from lumber in a study carried out in Prussia, finding that a profit of 12 per cent. of the pruning cost was realized. This revelation gave national economic importance to pruning. It removed all doubt in the minds of those who had previously viewed it askance, and proved that it was a sound and profitable silvicultural venture.

In 1865, Pressler showed scientifically and conclusively that pruning produced more cylindrically shaped boles than unpruned trees. He found that the diameter growth at any point on the stem is proportional to the amount of leaves above it and the annual rings were widest directly beneath the crown. Consequently, pruning enhanced the growth in the upper part of the pruned stem, the fulness is accelerated, and a more round log is the result. He advised, however, that in order to attain the maximum growth and most desirable form, great care should be taken in regulating crown length and the number of pruned trees per hectare.

According to May (1888), Uhlig, Göppert, Tramnitz, Gerwig, Von Mühlen, Von Schütz, Hartig, and Kienitz all contributed in a major way to the interest and progress that was maintained in Germany from 1850 to 1900 , when the popularity of pruning was at its height, for it was given much consideration and enjoyed wide usage during this period. In 1866 an effort was made to co-ordinate what had already been done with a view to establishing some workable rule by which pruning could be generally and satisfactorily applied. 
Schmuziger (1910) records that pruning was practised very extensively in southern Germany and Austria about 1870. During that period, when the demand for high-quality wood gradually replaced the intense demand for fuel following the scarcity of the latter product in the Middle Ages, knot-free lumber was at a premium and brought 30 per cent. more in price than lower grades containing knots. In an effort to prune on a large scale, lots were made saleable to the poorer landowners at exceedingly low sums of money for the purpose of having them prune the trees and use the prunings for fuel. The inability to provide expert supervision which was necessary for the success in such undertaking, was perhaps the reason for its abandonment after a number of years; and the green pruning of spruce and pine fell into discard. The effect of this evidently worked adversely, gradually spreading throughout the country, since towards the close of the century the interest in pruning appears to have waned.

The practice of pruning apparently spread to Sweden from the continent, probably around 1870 . According to Lundh (1924) it has never been customary there, since, when it was being generally accepted and employed in Germany and France, conditions favoring its introduction to the country were lacking-namely, intensive management and a market for the pruned material. There was, however, a small amount of pruning carried out during the latter half of the nineteenth century, but it was so restricted in scope, being of an experimental nature, that it reached no definite degree of perfection.

\section{ENGLAND 1900-1935}

From 1900 onwards until recent years, England made indifferent progress in the field of pruning. Among investigators of this time Whellens (1919) made an inspection of a number of sawmills in the British Isles, reporting that only 5 per cent. of the lumber examined was clear and free of knots. He did not recommend the pruning of live branches, but sug. gested close planting to produce a dead length and the subsequent pruning of the dead branches, accompanied by a judicious thinning as early as possible. He cited as an example a 25 year old Douglas Fir plantation pruned when the stand was 15 years of age, and again later, which produced lumber of such value that the operation was more than paid for, even at wartime labor wages.

Due to the drain on England's forest resources occasioned by the Great War, and economic conditions that have existed in recent years, a substantial reforestation and afforestation program has been strictly adhered to for some 15 years. As a result, many acres planted to conifers have reached a stage where intensive silvicultural measures have become neces- 
sary. Furthermore, the costs involved in this annual work have necessitated planting trees at distances which are not conducive to the self-pruning of many species. Consequently, pruning is gradually being accepted as a means of solving the problem of securing knot-free stems for the production both of clear lumber and of poles.

Ackers (1935) believes that it may pay to prune a number of species intended for different purposes, including poles for pit timber, oak as a final crop product, chestnut for furniture work, poplar for plywood, larch for planking, Douglas fir, Lawson cypress, Thuya and Sequoia for lumber, Scots pine for telegraph poles, Sequoia, Abies grandis, and Pinus insignis for poles and boxwood.

Guillebaud (1933) describes investigations into the pros and cons of pruning for various species on different sites and in widely scattered regions, which have recently been inaugurated by the research staff of the British Forestry Commission, in an effort to determine some of the fundamental laws governing pruning work on a practicable basis. Included in these are the financial aspects, technique, and the physiological reactions of the various individual species to methods, severity of treatment, and season of pruning. Stimulated by the prospects of a large pole market and a demand for high-quality lumber, pruning will doubtless find a permanent place in the management of English forests.

CONTINENTAL COUNTRIES 1900-1935

In the last 35 years pruning on the continent and in Scandinavian countries has been practised and investigated to a limited extent. France, Germany, Sweden, Spain, and Portugal appear to be the only countries which have continued in their efforts to further research in problems connected with quality production. Of these five, Germany has perhaps accomplished more than the others. This may be accounted for, partially at least, when one considers the predominance of hardwood forests which France maintains over softwoods, and Sweden's pulpwood requirements, which would necessarily eliminate old or intensively produced high-quality timber. In Spain and Portugal pruning is generally confined to the Cork oak forests.

Many ideas have been promulgated of late years in Germany which have heretofore been given only minor consideration, with a view to reaching and solving the most important problems connected with the subject of pruning. Junack (1931) dealing with Scot's pine, points out the necessity of "dry" pruning at the time of the first thinning, which he believes necessary for crop-tree production of high-quality wood. The question now is, to find the cheapest and most efficacious way to accomplish this. Junack 
contends that it has been definitely proven that green pruning of Scot's pine is injurious to subsequent growth, but that pruning of dying branches which have no further function for the tree is all that is necessary to attain sufficient pruned length. He cites examples where pruning has been profitably applied of late years for offsetting wind breakage, and for the production of litter, faggots, decorative material, and fodder.

Mayer-Wegelin (1932) advances additional queries for consideration, and believes that there are still many problems of pruning yet to be settled. $\mathrm{He}$ affirms that the question of quality is only partially solved by diameter growth, and that soundness is more often the key to the solution. $\mathrm{He}$ believes that volume and quality production should be more carefully analyzed in an effort to balance them, and that the question of vitality and branchiness of different species for various sites should be considered before any valuation is determined. He draws attention to the demand for knotless railroad ties in Germany and the usefulness of clear wood for carving purposes. With logical contention he points out the desirability of being in a position to answer many questions which will inevitably arise in the not distant future. He surmises that as foresters continue to exploit more extensive methods of silviculture for raising the value over a long period of time, intensive methods will not be feasible. He believes that pruning should primarily depend on silviculture rather than on contemplated profit, and that to-day it is more important to solve the questions of principle than to make a fruitless attempt for doubtful monetary gain.

Pruning at the present time in Germany is only sparingly carried out. ${ }^{1}$ The fact that thinnings have a marketability in Europe justifies the method of dense planting, and in most cases pruning is deemed unnecessary. A defective board in Germany is not considered so significantly in the light of values as in this country, and the few defects incurred by the method of natural regeneration and self-pruning are inconsequential. It is not impossible that much of the disfavor which has been characteristic of the attitude towards pruning was made manifest by the tardiness in the time that the operation has been carried out in the past. It resulted in many stands being pruned late in life, around 35 to 50 years of age, and it is likely that many large dead branches were prevalent on these stems. They undoubtedly required a long time to heal and in many cases produced unsightly defects and blemishes which detracted from the value of the wood. Pruning at such an age added little or no value to the final product, but rather diminished the worth of the lumber sawn.

1 Information on present attitude towards pruning in Germany and methods used in lieu of pruning was gathered in a letter to the author from Dr. C. A. Schenck, Darmetadt, Germany, November, 1933. 
Owing to the large amount of select softwood that is imported into Germany at the present time, she is undoubtedly not carrying on pruning as extensively as in the past, or endeavoring to solve the many questions connected with it, for the small amount of spruce and pine that is produced and consumed at home. In all events pruning appears to have reached a state of doldrums, and the feasibility of procuring satisfactory natural pruning in Norway spruce and Scot's pine appears substantial enough to warrant many subscribers to that viewpoint. The apparent danger from fungi and insects, the expense of operation, the damage on trunks caused by high pruning, the grazing by deer on pruned stems, the marketability of thinnings, and the small number of clear boards obtained, especially from spruce, all have tended to eliminate artificial pruning on a large scale in Germany and other European countries. It is cheaper and more satisfactory, they find, in the majority of cases to suppress the side branches by either securing natural regeneration of dense stocking or to adopt mixtures of light demanders and shade endurers for cleaning purposes.

France and Sweden can be said to be alike in their present attitude toward pruning. With the exception of a small amount of Maritime pine in the south of France, which is pruned to facilitate turpentine tapping, and a restricted and intensive amount on hardwoods (Woolsey, 1930), France relies chiefly on her colonies for quality supply.

In Sweden pruning is limited in extent and mostly experimental. Perry (1929) describes where pruning is resorted to as a means of protection against fungal attack in young aspen and poplar stands. Wesslen (1930) and Löf (1931) both describe recent pruning investigations, and conclude that substantial profits can be realized on both spruce and Scots pine on a seventy to ninety year rotation. In certain parts of Sweden a highly intensive method of pruning is carried out for the purpose of securing straight, well formed, and strengthened poles for use as ship masts.

Natividade (1932) ${ }^{1}$ records that pruning in Spain and Portugal is carried out for the multiple purpose of cork production, improving the form of cork oaks, enhancing acorn production, and allowing more light to reach the vegetative crops beneath the oak standards. Experiments have been instituted at the Portugal Forest Experiment Station to determine what method, severity, and season of pruning will produce most beneficial results, contrasted to the hap-hazard practice which has characterized previous pruning.

AUISTRALIA AND SOUTH AFRICA 1900-1935

Pruning in Australia and South Africa has been recently adopted, following their embarkation on extensive planting programs. In the three south.

1 Review by P. L. Buttrick, Journal of Forestry, Volume XXXIr, No. 1. 
erly states of Australia, where planting is being carried out at the rate of 5,000 acres annually on land unsuited to the establishment and growth of native species and where the growth of exotic conifers is abnormally rapid, pruning has been found to be of vast importance. Due to the excessive planting costs brought about by preparation of the land for conifer plantations, which often exceeds $\$ 50$. per acre, spacings of $8 \times 8$ or $10 \times 10$ feet have been adopted as a means of offsetting this unusually large initial cost. The canopy does not close in as rapidly as if closer spacing had been employed and the branches though moderately small, do not die and fall off for some time. Artificial pruning is considered a necessity to facilitate the pruning and cleaning of stems and the technique has already reached a remarkable degree of perfection. ${ }^{1}$ The method of pruning varies in different parts but in general, costs are such as to warrant the variation of ways in which it is carried out. Investigations have been under way since 1933 with a view to introducing power driven machines in order to speed up the work of pruning over large areas. The rapid growth experienced by Pinus insignis, Doug., the most commonly pruned tree, enhances the value of the operation to the extent that little time is lost before the cuts are entirely healed and clear wood is produced. ${ }^{2}$

Due to the fact that, with few exceptions, the entire commercial softwood supply of Australia is to be found in plantations, and since knot-free wood for boxes is in high demand as a direct aid in exporting one of Australia's basic products, dried fruits, pruning is foremost in the management of plantations and will doubtless continue to be for many years to come.

In South Africa, according to King (1925), Pinus insignis, Doug. is also found to be best suited for aforestation purposes and pruning is resorted to for the production of high quality lumber. The production of this wood from Montery pine is chiefly used to meet the demand for boxes and matchwood which requires knotless wood in a minimum time. This is accomplished, as in Australia, by pruning stands as soon as the lower branches begin to die which for Pinus insignis is from 7 to 10 years after planting, depending on the spacing.

\section{AMERICA $1900-1935$}

There has been very little pruning carried out on a commercial scale in North America, and still less investigative work, until the present time. This is chiefly due to the fact that until the past few years little importance was attached to the significance of pruning as a silvicultural measure. Furthermore, the extensiveness of forest practice has been such that the idea of pruning was

1 Alexander Rule, Federal Forestry Bureau, Canberra, Australia, in a letter to the author, December, 1933.

2 A. V. Galbraith, Chairman Forestry Commission, State of Victoria, in a letter to the author, January, 1934 
overlooked and in its place, the more generally accepted methods of obtaining the same result by thinning and cutting practices and the use of mixed stands, have been the vogue. In addition to this, the prime object of land owners and public agencies has been rather to produce the greatest quantity in the least possible time and the problem of quality has been overlooked. The virgin stands of many of the commercial species are still to be exhausted and for this reason alone, there has apparently been no inducement to have concern for the production of quality wood by artificial methods.

Pruning on a commercial scale was initiated in America, Butler (1925), Cline and Fletcher (1928), especially in New England, by a few devout supporters of the practice on their private lands but only a few of these people attacked the problem from a purely silvicultural angle. In most instances, the idea was evidently one of appearance rather than a desire for the more beneficial effects conducive to quality production. In other cases, the owners sought to create situations where their stands would be immune from the ravages of fire. Others have contrived to escape the damage from blister rust by pruning affected and adjacent limbs. This most often resulted in the pruning of every tree in the stand and the costs of such work naturally became excessively high and prohibitive for the average owner. Consequently, pruning received a setback as a result of such misleading methods. Furthermore, the majority of the work was done with an axe and as a consequence, large and unsightly wounds resulted with prolific exudations of pitch. It was rightly presumed that these wounds would require much time to heal and when they were finally occluded, serious defects would result in the subsequent wood in the form of pitch pockets and discoloration. This method and its dire results did much to misconstrue the worth of pruning correctly done and those who had previously conceived of it as a valuable practice joined the ranks of those who condemned it.

In the last five years, however, pruning has been received with much more favor and consideration than it ever did formerly. Although many private owners are still dubious as to the practice, a much larger percentage of them are resorting to pruning than was previously the case. In many school and state forests, and company holdings, pruning is a regular part of the management and on a sound financial basis, for the purpose of producing clear lumber of high quality. The practice has been extended to several species and the objects of the operation have been made to include a wider range than heretofore. An example of this is to be found where Cline and MacAloney (1931) presented a practicable system of reclaiming severely weeviled white pine plantations in such a way that a moderate profit may be expected from the treatment. Others have considered carrying out pruning 
for the purpose of improving bole form as a more desirable product for poles.

Very little investigative work has been carried out in the field of artificial forest pruning in North America. Many articles and recommendations have been written on the advisability of such work, its benefits, disadvantages, etc., but with some exceptions, there appears scant analytical and conclusive material upon which sound opinions may be based. Foster (1913), Frothingham (1914), Knapp (1915), Tunis (1923), Richardson (1928), Young (1933) and Simmons (1935) have contributed to pruning literature in a general kind of way, recommending it as suitable to apply to increase wood quality (of white pine in most cases) on short rotations.

In the textbooks of Graves (1911), Moon and Brown (1927) and Hawley (1929) reference is made to methods, costs, objects of pruning and the results which may be expected to follow. In a general way Graves points out the advantages of pruning to obtain clear lumber but explains that it is only practised on intensively managed areas, where natural pruning fails or does not suffice and where the rotation is comparatively short. In this way, valuable results may be obtained for relatively little expense and will yield a sub. stantial profit on the outlay of the trees concerned.

Moon and Brown's recommendations follow along similar lines but take care to predict the apparent defect resulting from the removal of green branches. Hawley, on the other hand, who devotes considerable space to the subject of pruning, contends that in order to produce a satisfactory percentage of clear lumber on a 60 to 80 year rotation, a certain amount of green pruning will be necessary. He suggests pruning the trees as high as the crowns are in contact and points out the increase in expense as pruning is carried up the bole. For all practical purposes, he advises that pruning should be confined to the butt log which will vary from 18 to 20 feet. In regard to removing green crown, Hawley explains that if more than 50 per cent of the living crown is removed, height growth for the years immediately following pruning will be reduced about one-third that of the unpruned tree. He also cites the probable dangers which are incurred from the pruning of green limbs from conifers and suggests ways to overcome them, insofar as it is possible.

In the field of published research Cline and Fletcher (1928), Hicock (1931), Schenstrom (1931), Paul (1931), (1933), Demmon (1934), Hawley and Clapp (1935) and Curtis (1936), have contributed most of what is available for application. While most of the investigative work has been confined to New England, Demmon and Paul, and Schenstrom, studied the possibilities of pruning loblolly pine in the South and Douglas Fir second growth in the Pacific Northwest.

In line with the interest and progress in artificial forest pruning that is currently prevalent, improved tools have been lately introduced for more 
satisfactory and faster work. Cuno (1935), Rich (1935) and Hawley (1935) describe progress in this phase of pruning.

Recent investigations, Spaulding et al $(1935)$ have shown that the fungus Stereum sanguinolentum which grows as thin, flat patches $1 / 2$ to 2 inches across on the wood or bark, is capable of causing extensive damage in the form of heart rot on pruned Northern white pine. It has already caused serious losses in living trees of Alpine and Balsam Fir in temperate North America and in Scots Pine and Norway Spruce in Scandinavia.

It is highly improbable that the amount of pruning completed to date in New England will have any effect on the market as a whole when the present second growth stands reach maturity. Artificial pruning is currently justified in the belief that as the Pacific Coast supplies of high quality material dwindle in the next 30 to 50 years, pruned material will fill the gap and find a ready market with prices in keeping with the grades produced. Where studies have dealt with the feasibility of artificial pruning, all cases have shown that as long as the price differential which has existed at the time of the study continues and a suitable market is at hand, the practice can be warranted.

It is of questionable value to quote statistics accurately reflecting conditions which have existed in the past and which prevail at present. Consequently, at best they are only an approximate guide to an interpretation of economic trends. Available figures ${ }^{1}$ on the fiber board box industry show that this phase of production increased 50 percent. from 1924 to 1928 . Also, from 1912 to 1924 , the percentage of wood shipments decreased from 78.1 to 45.2 for this period while the production of paper and fiber board increased from 21.9 to 54.8. However, the loss of lumber sales occasioned by the increased use of the fiber board business cannot be given too much weight inasmuch as research has found uses for the paper box where no market existed for lumber previously.

Current trends would indicate that the fiber box industry will continue to expand and thus replace to a marked extent at least, the loss of the box board market which it created. It is likely, also, that by a judicious pruning program, operators, especially in New England, will be able to produce a high grade of knot-free lumber which will also help to offset any drop in demand caused by the decline of wooden box containers. The better grades of clear white pine used for the manufacture of pattern stock, panelling, high class fabricating material which can be easily worked, have always found a ready market in New England.

The importance of artificial forest pruning cannot be overlooked or summarily dismissed. There are many problems yet to be solved connected with

1 Divigion of Forest Economics, Forest Service, U.S.D.A. 
the advisability and applicability of its practice that warrant much research and extensive investigation for species which constitute the bulk of plantations and the understocked stands of natural regeneration. It is hoped that this article will reveal some phases of development and results in pruning, both past and recent, that older countries have experienced and that we in North America, appreciating the value of discernment, will profit by their experience to cope with what may be our lot in future years.

\section{REFERENCES CITED}

(1) Ackers, C. P. The Financial Aspects of Pruning. Quarterly Journal of 1933 Forestry, Vol. 27:189-203.

(2) Alers, Georg. Uber das Aufasten der Waldbäume: durch Anwendung der 1874 Hohen-oder Flügelsäge. Edit. 2, Frankfurt. 92 p.

(3) Butler, O. M. The Pine Pruner of Holdnerness. American Forests and 1925 Forest Life. Vol. 31:92-94, illus.

(4) Cline, A. C. and Fletcher, E. D. Pruning for Plofit. Harvard Forest 1928 and Massachusetts Forestry Association: $23 \mathrm{p}$., illus.

(5) - and MacAloney, H. J. A Method of Reclaiming Severely 1931 Weeviled White Pine Plantations. Massachusetts Forestry Association. Bull. No. 153: 11 p.

(6) Courval, E. A. de. Das Aufasten der Waldbäume: oder, Neue Methode der 1865 Behandlung der hochstämmingen Hölzer: aus dem Französischen von C. J. W. Höffler, pl. 15, $8 \mathrm{~cm}$. Berlin, 74 p.

(7) Cuno, John B. Power Pruning. Journal of Forestry Vol. 33: 753-754. 1935

(8) Curtis, James D. A method of Pruning Dead Branches. Forestry 1936 Chronicle. Vol. XII:291-299.

(9) Demmon, E. L. Annual Report, Southern Forest Experiment Station, 1934 New Orleans, La.

(10) Evelyn, John. Silva or a Discourse of Forest Trees and the Propagation 1706 of Timber. 4th Edition. Published by Express Order of the Royal Society. Printed for Robert Scott in Little-Britain; Richard Chriswell in St. Paul's Churchyard; George Sawbridge in Little-Britain; and Benj. Tooke in Fleet street. pp. 206-215.

(11) Foster, J. H. Pruning the Pine Woodlot. Durham, N. H., New Hamp1913 shire Agricultural Experiment Station Press Bulletin 37: $1 \mathrm{p}$.

(12) Frothingham, E. H. White Pine Under Management. United States 1914 Department of Agriculture, Bulletin No. 13:38-39.

(13) Garver, R. D. et al. Selective Logging-In the Loblolly Pine-Hardwood 1931 Forests of the Middle Atlantic Coastal Plain with special reference to Virginia, Virginia Forest Service Publication No. 43: p. 55 .

(14) Gillanders, Alex T. Pruning-Its Ornament and Utility. Transactions of 1887 the Royal Scottish Arboricultural Society, Vol. 2: 49-54.

(15) Graves, H. S. Principles of Handling Woodlands. First Edition, John 1911 Wiley \& Sons, Inc., New York, p. 223.

(16) Gillebaud, W. H. Pruning in Plantations. (Reprint of Quarterly Journal 1933 of Forestry, Vol. 27), $29 \mathrm{p}$.

(17) Hawley, Ralph C. The Practice of Silviculture. Second Edition, John 1929 Wiley \& Sons, Inc., New York. pp. 168-172.

(18) and Clapp, R. T. Artificial Pruning in Coniferous Plantations, 1935 Yale University, School of Forestry, Bull. No. 39: 36 p., Illus.

(19)

1935 32: 1009.


(20) Hicock, Henry W. Pruning in Young Plantations, Journal of Forestry, 1931 Vol. 29: 541-543.

(21) Hutchison, Robert. On the Pruning of the Rarer Conifers. Transaction 1868 of the Royal Scottish Arboricultural Society, Vol. 4: 170-176.

(22) Junack, Karl. Trockenästung an Keifern. il. Forstarchiv, Vol. 7: $1931255-259$.

(23) Kienitz, — - Uber die Aufästung der Waldbäume. supple. All. F. u. 1878 Jagd: p. 58.

(24) King, N. L. Pinus insignis Doug. in South Africa. Forest Department, 1925 Union of South Africa, Pretoria Bulletin 15: 20-21.

(25) Knapp, Frederick B. Silviculture of White Pine (Pinus strobus) 1914 Massachusetts Forestry Association, Boston. Bulletin 106: $1 \mathrm{p}$.

(26) Löf, Axel. Virkeskvaliténs höjande genom uppkvistning. Skogen, Vol. 1931 18: 3-7, 25 figs.

(27) Lundh, Erik. Den a Böda kronopark utföıda grönkvistningen av. tall. 1924 Meddlelanden fran Statens skogsförsöksanstalt 21: 49-100.

(28) Lawson, William. A New Orchard and Garden or the best way for plant1623 ing, grafting, and to make any ground good for a rich orchard. First Edition. Printed at London by I. H. for Roger Jackson, to be sold at his shop near Fleet street, Conduit. (Orchards Cap. 11).

(29) May, K. J. Die Entwickelung der Aufästungstechnik und Aufästung1888 slehre seit 1860: ein Beitrag zur Geschichte des deutschen Waldbaues. Inaugraldissertation. $\mathrm{cm}$. München. Theilweiser Abdruck der Geschichte Aufästungstechnik und Aufästungslehre. $55 \mathrm{p}$.

(30) Mayer-Wegelin, H. Astigeit und Astung. Sonderabdruck aus Forstal1932 chiv, Vol. 8: 261-266.

(31) McCorquodale, Wm. On Judicious Pruning. Transactions of The Royal 1884 Scottish Arboricultural Society, Vol. 10: 166-171.

(32) Michie, C. Y. Practice of Forestry. First Edition, Wm. Blackwood \& 1888 Sons, Edinburgh and London, pp. 209-301.

(33) Moon, F. F. and Brown, N. C. Elements of Forestry. First Edition. 1927 John Wiley \& Sons, Inc., New York, p. 93.

(34) Natividade, J. Viera. Poda dos Sobreiros, Direction General, Service of 1932 Forestry and Agriculture. Bulletin of the Ministry of Agriculture, 13th year. No. 2. First Series, Lisbon, Portugal. 29 p.

(35) Nichol, Walter. The Practical Planter Comprehending the Culture and 1799 Management of Planted and Natural Timber in every Stage of Its Growth. First Edition, printed for author, Edinburgh. p. 213.

(36) Paul, Benson H. Pruning Young Loblolly Pine Trees Makes Timber 1931 Growing More Profitable. Southern Lumber Journal. Vol. $35: 32$. (37) 1933 31: 563-566. Pruning Forest Trees. Journal of Forestry. Vol.

(38) Perry, G. S. Forestry in Sweden. First Edition. Published by the author. pp. 119, 203.

(39) Philip, Robert. On pruning forest trees. Transactions of The Royal 1863 Scottish Arboricultural Society. Vol. 2: 11-16.

(40) Pontey, William. The Forest Pruner or Timber Owner's Assistant: A 1805 treatise on the training or management of British Timber trees. Second Edition. J. Harding, Huddersfield. 277 p. 
(41) Rich, J. H. A New Forest Pruning Tool. Journal of Forestry. Vol. 33: $1935 \quad 1006-1007$.

(42) Richardson, A. H. Forest Tree Planting. Department of Lands and 1928 Forests, Ontario. Bull. No. 1, p. 39.

(43) Schenström, S. R. Pruning Experiments in Second Growth Stands of 1931 Douglas Fir. Forestry Chronicle, Vol. 7: 220-234.

(44) Simmons, E. M. Pruning and Thinning a White Pine Plantation in the 1935 Southern Appalachians. Journal of Forestry, Vol. 33: 519522.

(45) Spaulding, Perley, et al. Stereum sanguinolentum, a dangerous fungus 1935 in pruning wounds on Northern White Pine, U.S.D.A. Technical Note No. 19.

(46) Tunis, Theophilus. Forestry for Proft. First Edition. Geo. Putnam, 1923 London, N.Y. 296 p.

(47) Young, Donald A. A Thinning and Pruning Operation in the Appal1933 achians. Forest Worker. Vol 9(4): 10.

(48) Wesslen, Stig. Uppkvistning. Skogen. Vol. 17: 589-591. 1930

(49) Whellens, W. H. The Importance of Pruning. Transactions of the 1919 Royal Scottish Arboricultural Society. Vol. 33: 84-86.

(50) Woolsey, T. S., Jr. Studies in French Forestry. First Edition, John 1920 Wiley \& Sons, New York. pp. 189, 278, 300. 